\title{
Epidemiology of COVID-19 in Africa: daily cumulative index and mortality rate
}

\author{
Kenneth Bitrus David ${ }^{1}$, \\ Naomi Thomas' ${ }^{2}$, Joan Kuyet Solomon ${ }^{1}$ \\ ${ }^{1}$ Faculty of Pharmaceutical Sciences, \\ Kaduna State University, Nigeria \\ ${ }^{2}$ Faculty of Pharmaceutical Sciences, \\ Ahmadu Bello University Zaria, Nigeria
}

\begin{abstract}
The COVID-19 outbreak which originated from Wuhan, a city in China, has spread to over 180 countries in the world, disrupting several sectors of human life, and causing deaths. This unprecedented event has affected 55 countries in Africa. This study aims to outline the current epidemiological data of COVID-19 in Africa. The number of confirmed cases and deaths in Africa was obtained from the COVID-19 Dashboard by the Center for Systems Science and Engineering (CSSE) at Johns Hopkins University. Mortality rate and daily cumulative index were calculated for each country. The results indicated that the mortality rate in Africa was low compared to other continents regardless of the high Daily Cumulative Index recorded.
\end{abstract}

Keywords: COVID-19, epidemiology, mortality, Africa

\author{
Corresponding Author \\ Kenneth Bitrus David \\ Faculty of Pharmaceutical Sciences, Kaduna State University, Nigeria \\ E-mail:kennethdavidb@gmail.com
}


Coronaviruses are a group of RNA viruses so named because of their outer fringe of envelope proteins resembling a crown (known as 'corona' in Latin). ${ }^{1}$ They are zoonotic and often cause mild to severe upper respiratory tract infections in humans. In 2003 and 2012, there were outbreaks of infection causing severe acute respiratory syndrome (SARS) and Middle-East respiratory syndrome (MERS) respectively. ${ }^{2}$ The novel coronavirus disease also known as COVID-19, caused by a virus known as SARS-Cov-2, started at Wuhan in China, crossed to many other countries in the world, and was declared an epidemic by the World Health Organization (WHO) on $11^{\text {th }}$ March 2020.3,4 The burden caused by this pandemic is devastating.

The countries with the greatest number of COVID-19 cases and related deaths include: United States of America, Spain, Italy, France, Germany, United Kingdom, Turkey, China, Iran and Russia. ${ }^{5}$ Thus, it is speculated that warmer temperatures tend to limit the spread of the infection. This has led to the assumption that European countries and other temperate regions will experience higher morbidity and mortality rates than African countries. However, there has not been any strong evidence to either confirm or debunk this speculation. ${ }^{6}$

The aim of this article is to provide some epidemiological parameters that will guide future research on COVID-19 in Africa as there has not been any published article containing the epidemiological parameters of COVID-19 pandemic cases in all African countries, hence the need for this letter. This is imperative as simple counts on individual confirmed cases can be misleading indicators of the pandemic's trajectory if these counts are limited by problems in access to care or bottlenecks in laboratory testing, or if only patients with severe symptoms are tested.?

As of $18^{\text {th }}$ May 2020 11:44pm GMT, Africa recorded a total of 87,925 confirmed COVID-19 cases in 55 countries with highest number of cases found in South Africa - 16433 (18.7\%), Morocco - 6952 (7.9\%), Ghana - 5735 (6.5\%), Egypt - 12229 (13.9\%), Algeria - 7019 (8.0\%), and Nigeria - $5959(6.8 \%)^{8}$ (Table I). In a bid to reduce the rate of transmission, 23 countries including China and USA imposed a ban on international flights by $31^{\text {st }}$ January, 2020. South Africa, on $18^{\text {th }}$ March was the first African country to impose a ban on foreigners who had visited high-risk countries such as China. Other countries followed suit. Since there is a ban on international flights, the tendency of having further imported cases of COVID-19 is unlikely, implying that new cases recorded are due to local transmission. However, due to the asymptomatic nature of the disease and diagnostic insufficiency, local transmission and underreporting are expected to increase, consequently posing a threat to the global health. ${ }^{9}$

The daily cumulative index (DCl) for each country was obtained by dividing the cumulative cases by the number of days between the first reported case and $18^{\text {th }}$ May, 2020. South Africa has the greatest DCl (216.2), followed by Egypt (134.4), Morocco (90.3), Algeria (85.7), Ghana (83.1), and Nigeria (72.7). More than $50 \%$ of African countries have a $\mathrm{DCl}$ value less than 5.00. Recent research outlined South Africa, Algeria, and Egypt as countries with the highest importation risk from China hence the high incidence rate in these countries. ${ }^{9}$

The mortality rates due to COVID-19 in Africa vary from country to country but have been relatively low compared to those recorded by European countries and other regions. It is noteworthy that the mortality rate recorded by countries may not be the actual death rates as the estimation is based on the number of deaths in relation to confirmed cases. The full denominator is not usually obtained accurately as patients with very mild symptoms might not be tested and hence remain unidentified. It is assumed that the maximum incubation period of COVID-19 is up to 14 days, whereas the average number of days from onset of symptoms presentation to becoming critically ill is around 10 days. It was reported by the WHO recently that it takes from about 2 to 8 weeks between onset of symptoms and death. ${ }^{10}$

\section{Conclusion}

African countries recorded a high daily number of confirmed cases but have a relatively low mortality rate. This is an indication that adequate measures are being put in place in order to curb the impact of this pandemic. The research community has responded 


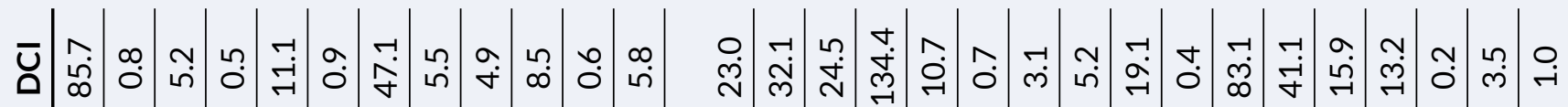

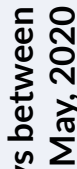

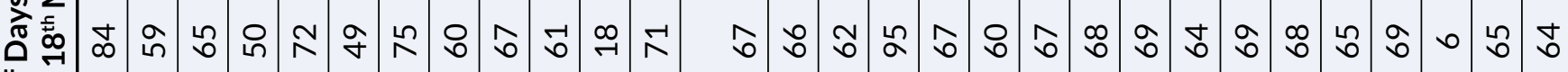
每

है

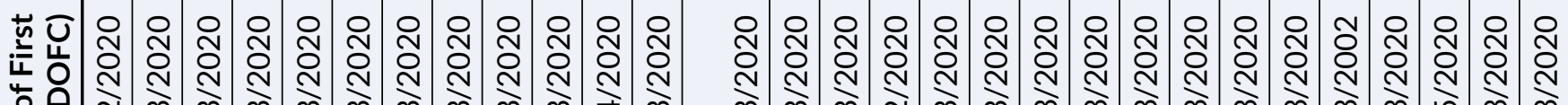

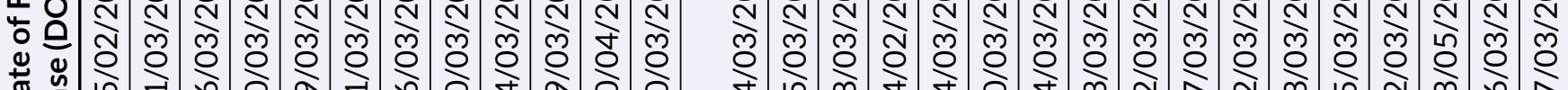

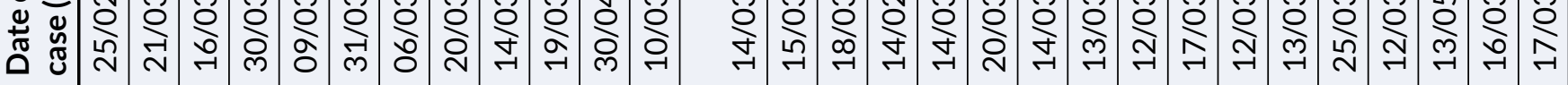

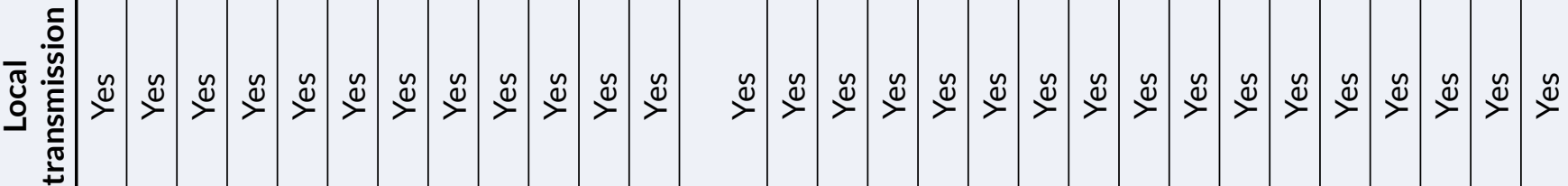

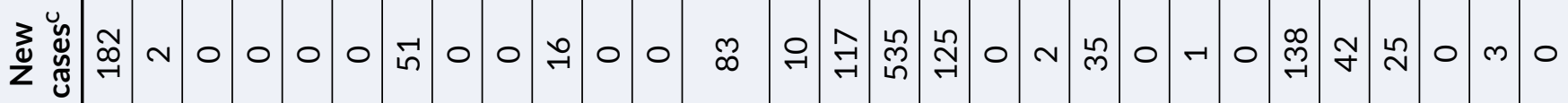

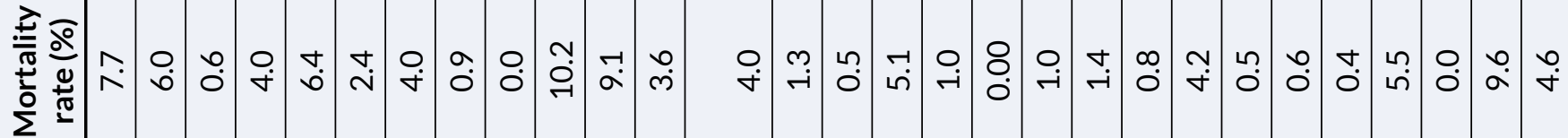

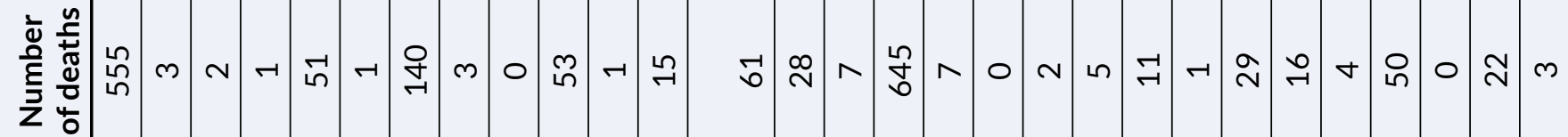
常

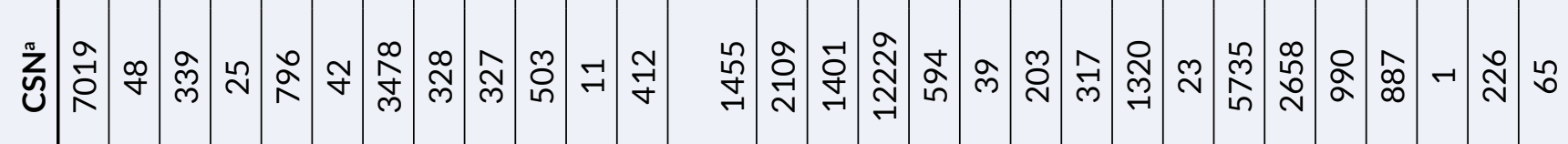

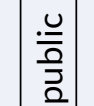

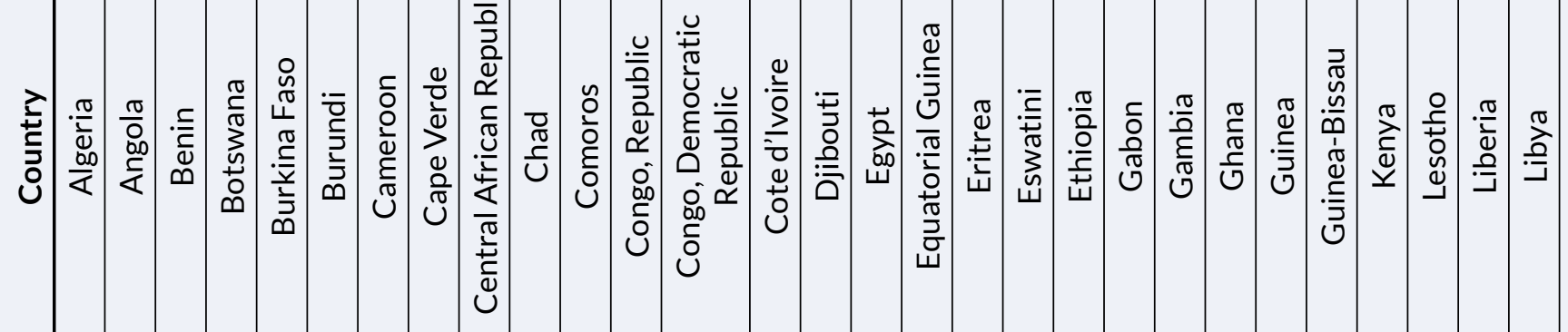




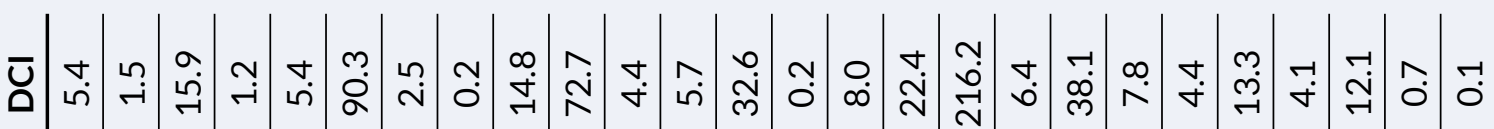

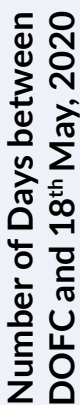

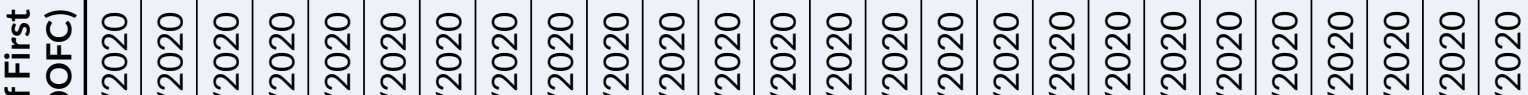
ㅇำ

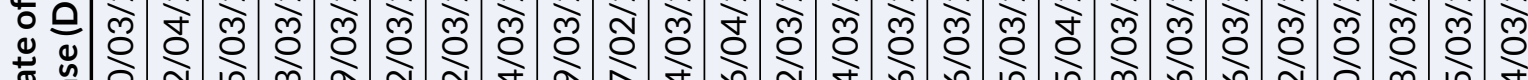

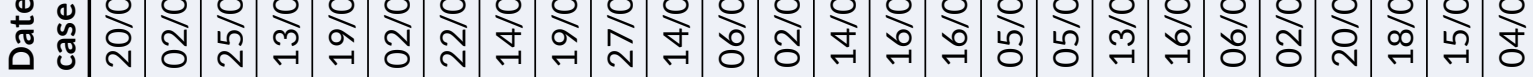

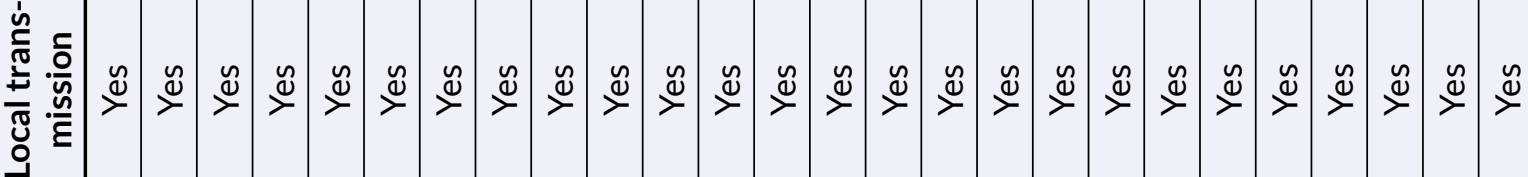

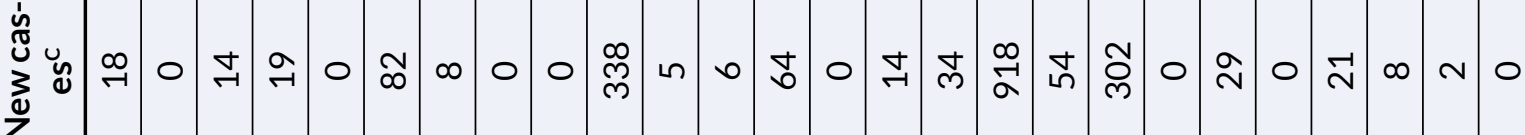

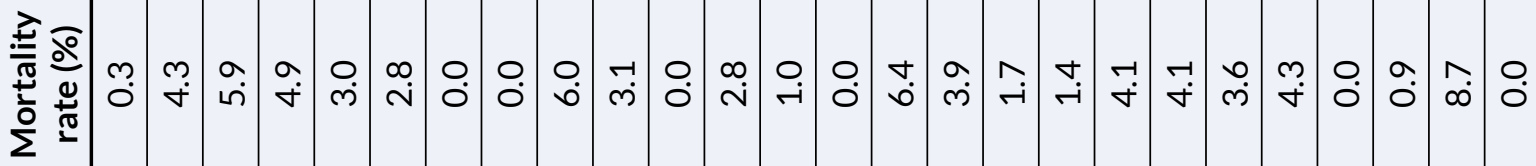

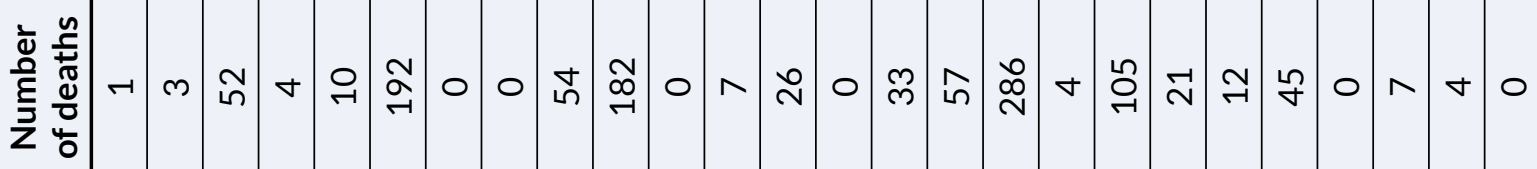

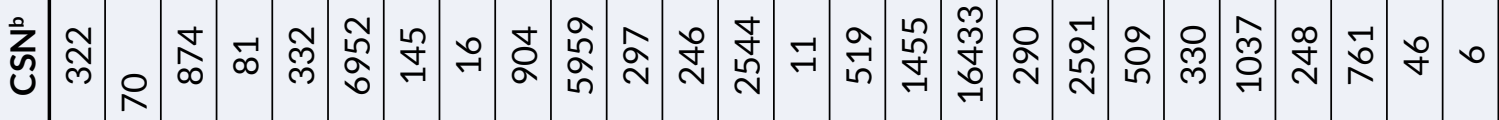

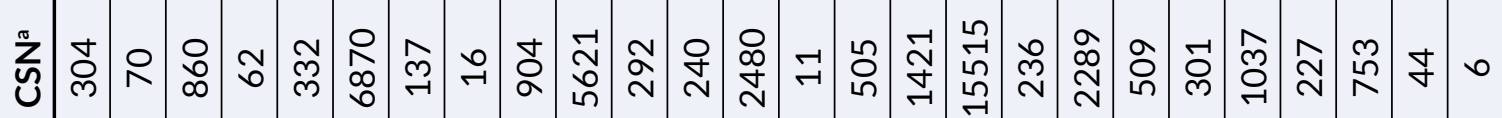

ธิจิ

ฮั่

$\sum_{i}^{i}$

要

产

幽

बृ

일

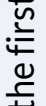

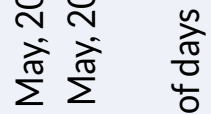

志志里

+艹 茂 紊

帘

㐫 㐫 $\frac{\text { "I }}{\text { है }}$

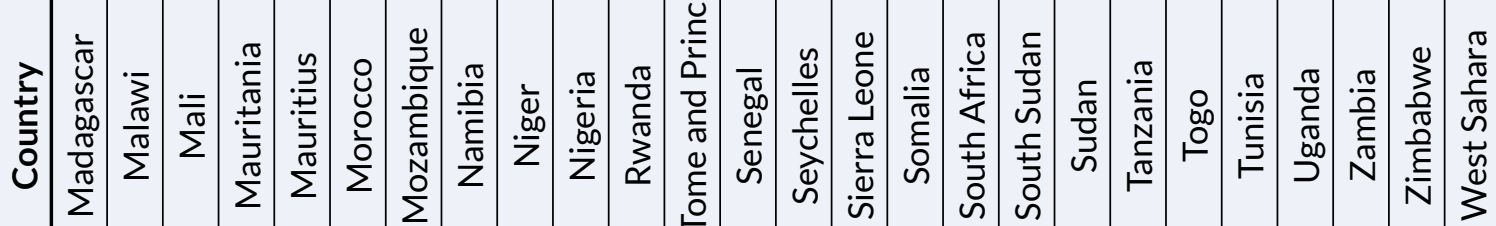

ڤ

U U U

芫 竞 艺

至 范

紊紊譬产 
to the COVID-19 pandemic in the world by carrying out studies to help understand the virus and provide ways of fighting it. However, not much attention has been given to the epidemiological studies of the virus in most regions. The impact of an epidemic is directly related to the number of people affected. Thus, further studies should be conducted on epidemiological patterns of COVID-19 in other regions so as to fully forecast the potential impact of the pandemic on life and the society. Evidence generated will help governments and health professionals to put measures in place to further flatten the curve of the disease.

\section{Competing interests}

The authors declare no competing interests.

\section{References}

1. Burrell CJ, Howard CR, Murphy FA. Chapter 31 Coronaviruses. In: Burrell CJ, Howard CR, Murphy FA, Editors. Fenner and White's Medical Virology (Fifth Edition). Academic Press; London: 2017, 437-446. https:// doi.org/10.1016/B978-0-12-375156-0.00031-X

2. Roy D, Tripathy S, Kar SK, Sharma N, Verma SK, Kaushal V. Study of knowledge, attitude, anxiety \& perceived mental healthcare need in Indian population during COVID-19 pandemic. Asian J Psychiatr 2020; 51: 102083. https://doi. org/10.1016/j.ajp.2020.102083

3. Holshue ML, DeBolt C, Lindquist S, et al. First case of 2019 Novel Coronavirus in the United States. N Engl J Med 2020; 382: 929-936. https://doi.org/10.1056/NEJMoa2001191

4. World Health Organization (WHO). Rolling Updates on Coronavirus Disease (COVID-19) https://www.who.int/ emergencies/diseases/novel-coronavirus-2019/events-asthey-happen (Accessed 18 April 2020).

5. European Centre for Disease Prevention and Control (ECDC). Situation update worldwide, as of $18^{\text {th }}$ May, 2020. https:// www.ecdc.europa.eu/en/geographical-distribution-2019ncov-cases (Accessed May 18 2020).

6. Topping A. Coronavirus: medical chief says UK hopes to delay any outbreak until summer. The Guardian. https://www. theguardian.com/world/2020/feb/13/coronavirus-medicalchief-says-uk-hopes-to-delay-any-outbreak-until-summer (Accessed 18 May 2020).
7. Lipsitch M, Swerdlow DL, Finelli L. Defining the epidemiology of Covid-19 - Studies Needed. N Engl J Med. 2020; 382(13): 1194-1196. https://doi.org/10.1056/NEJMp2002125

8. JohnsHopkinsUniversityandMedicine.COVID-19Dashboard by the Center for Systems Science and Engineering (CSSE) at Johns Hopkins University. 2020. https://coronavirus.jhu.edu/ map.html (Accessed 18 May 2020).

9. Atlantic Council. Barriers to mass testing for COVID-19 in Africa. 2020. https://atlanticcouncil.org/blogs/africasource/ barriers-to-mass-testing-for-covid-19-in-africa/ (Accessed 18 May 2020).

10. Backer JA, Klinkenberg D, Wallinga J. Incubation period of 2019 novel coronavirus (2019-nCoV) infections among travellers from Wuhan, China, 20-28 January 2020. Euro Surveill 2020; 25(5): 2000062. https://doi.org/10.2807/15607917.ES.2020.25.5.2000062 